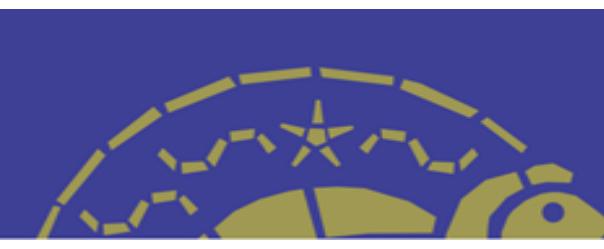

\title{
O NÚCLEO DE ESTUDOS AÇORIANOS: \\ UM OLHAR SOBRE A EXTENSÃO NA UNIVERSIDADE FEDERAL DE SANTA CATARINA
}

\section{Resumo}

Carla Cristina Dutra Búrigo

Universidade Federal de Santa Catarina carla.burigo@ufsc.br

O objetivo deste artigo é compreender na visão dos gestores sobre as ações do Núcleo de Estudos Açorianos (NEA) no processo de desenvolvimento da atividade de extensão da Universidade Federal de Santa Catarina (UFSC). A pesquisa desenvolvida foi um estudo de caso, de natureza qualitativa. A coleta das informações foi realizada por meio de entrevistas semiestruturadas com gestores dos últimos dez anos, envolvidos no processo de desenvolvimento da atividade de cultura e de extensão da UFSC. A investigação evidencia uma contradição a ser superada, ou seja, o NEA, ao mesmo tempo em que é situado como uma prática de gestão, esta mesma prática é negada pela carência de uma Política Institucional de Cultura e Extensão. Neste contexto, o NEA, como atividade de extensão, fica a mercê do desejo da prática de gestão, desarticulado de um querer institucional, de uma Política Institucional.

Palavras-chave: Extensão. Cultura. Gestão Universitária.

\section{THE AZOREANS STUDIES CENTRE: A LOOK AT THE EXTENSION IN SANTA CATARINA FEDERAL UNIVERSITY}

Abstract

The purpose of this article is to understand the vision of managers about the actions of Azoreans Studies (NEA) in the process of development of the activity of extension of the Federal University of Santa Catarina (UFSC). The research developed was a case study of a qualitative nature. Data collection was conducted through semi-structured interviews with managers of the last ten years, involved in the development process of culture activity and extension of UFSC. The research highlights a contradiction to be overcome, the NEA at the same time it is situated as a management practice, this same practice is negated by the lack of an institutional policy of Culture and Extension. In this context, the NEA as an extension activity, is at the mercy of the desire of practice management, inarticulate an institutional will, an Institutional Policy.

Keywords: Extension. Culture. University Management.

\section{EL NUCLEO DE ESTUDIO AZORIANOS : UNA MIRADA A LA EXTENSIÓN EN UNIVERSIDAD FEDERAL DE SANTA CATARINA}

Resumen

El propósito de este artículo es comprender la visión de los administradores acerca de las acciones del Nucleo de Estudios Azorianos en el proceso de desarrollo de la actividad de extensión de la Universidad Federal de Santa Catarina (UFSC). La investigación desarrollada fue un estudio de caso de naturaleza cualitativa. La recolección de datos se realizó a través de entrevistas semiestructuradas con los gerentes de los últimos diez años, que participan en el proceso de desarrollo de la actividad de la cultura y la extensión de la UFSC. La investigación pone de relieve una contradicción que hay que superar, es decir, el NEA, al mismo tiempo que se sitúa como una práctica de gestión, esta misma práctica es negada por la falta de una política institucional de Cultura y Extensión. En este contexto, la NEA como una actividad de extensión, está a merced de la voluntad de la gestión de la práctica, inarticulada una voluntad institucional, una política institucional.

Palabras clave: Extensión. Cultura. Gestión de la Universidad. 
O núcleo de estudos açorianos: um olhar sobre a extensão na Universidade Federal de Santa Catarina

\section{CONSIDERAÇÕES INICIAIS}

O presente artigo apresenta um recorte de uma pesquisa realizada junto ao Núcleo de Estudos Açorianos (NEA) (PEREIRA, 2015), com o objetivo de compreender, na visão dos gestores, sobre as ações do NEA no processo de desenvolvimento da atividade de extensão da Universidade Federal de Santa Catarina (UFSC).

O Núcleo de Estudos Açorianos é um Projeto de Extensão da UFSC, que possui como objetivo valorizar, preservar e divulgar a herança cultural trazida pelos imigrantes açorianos que chegaram em meados do Século XVIII em Santa Catarina (UFSC, 1984).

De acordo com o Fórum de Pró-Reitores de Extensão das Universidades Públicas Brasileiras (FORPROEX) a extensão visa interligar a universidade em suas atividades de ensino e pesquisa com as demandas da sociedade, fazendo com que a universidade cumpra o seu compromisso enquanto instituição social (CHAUI, 2003). Dessa forma, os projetos extensionistas desenvolvidos pela universidade devem ser uma resposta permanente aos anseios da sociedade garantindo os valores democráticos, de igualdade e de desenvolvimento social. (FORPROEX, 2001).

As metas do Plano Nacional de Cultura (PNC), aprovadas em dezembro de 2011 (BRASIL, 2012), afirmam que o Brasil deve desenvolver políticas e leis que protejam e promovam expressões culturais, entre elas as populares e tradicionais, como também trazer os conhecimentos e expressões culturais populares para dentro do contexto educacional.

De acordo com Leal (2007), a cultura tem demonstrado ser um dos fatores que facilitam a interação entre os diferentes grupos ou segmentos da sociedade. A preservação da história e da identidade social reforça que a cultura é um valioso elemento para a inclusão social.

Neste contexto, o NEA como fenômeno de investigação deste artigo, é uma possibilidade concreta de fortalecimento e socialização da cultura, por meio de suas ações extencionistas. Todavia, entre a Política Pública e a Política Institucional, há um caminho a ser percorrido que perpassa pela gestão universitária.

Isto posto, para atingir o objetivo inicialmente proposto neste artigo, partiremos do que dispomos de mais concreto, ou seja, o Núcleo de Estudos Açorianos, após refletiremos sobre o processo histórico da Política de Extensão e de Cultura, no âmbito público e institucional. Depois apresentamos o caminho metodológico percorrido para o desenvolvimento da pesquisa (PEREIRA, 2015), bem como, uma síntese das categorias analisadas, a partir da visão dos 
O núcleo de estudos açorianos: um olhar sobre a extensão na Universidade Federal de Santa Catarina

gestores, sobre o fenômeno investigado. Por fim, em um sentido contrário, retornamos ao ponto inicial, almejando desvelar outros olhares e possibilidades que esta caminhada possa nos propiciar.

\section{O NÚCLEO DE ESTUDOS AÇORIANOS}

A Universidade dos Açores (Portugal) e a Universidade Federal de Santa Catarina (Brasil), em 05 de abril de 1984, firmaram um Convênio de Cooperação e Intercâmbio (UFSC, 1984), no qual as referidas instituições de ensino superior se comprometem a realizar o intercâmbio de atividades visando o aprimoramento do ensino, da pesquisa e da extensão. Com o referido convênio, naquele mesmo ano, foi criado o Núcleo de Estudos Açorianos da UFSC, um projeto de extensão que tem como objetivo valorizar, preservar e divulgar a herança cultural trazida pelos imigrantes açorianos em Santa Catarina.

A Ilha de Santa Catarina reúne mais de dois séculos de história e cultura com raízes açorianas. O litoral do Estado de Santa Catarina, a partir das suas características históricas e geográficas, possibilitou o desenvolvimento de uma cultural tradicional, cuja base demográfica é originária do Arquipélago dos Açores-Portugal. (FARIAS, 1998).

Desde a chegada dos primeiros grupos de açorianos ao Brasil Meridional, a partir de 1748, que vieram colonizar as terras da Província de Santa Catarina, e terras de São Pedro do Rio Grande, houve adaptações e transformações em seu modo de viver e de ser desses povos. Contudo ações foram e estão sendo realizadas para que se possa revitalizar elementos da cultura açoriana em manifestações folclóricas, danças, literatura popular, religiosidade, produção artesanal e até mesmo na gastronomia. Estudos etnográficos auxiliam a conhecer as pessoas e cada realidade cultural, para que façam sentido as suas práticas, costumes, concepções e as transformações pelas quais estas passam. (FARIAS, 1998).

O NEA está vinculado a Secretaria de Cultura (SeCult), atuando em mais de 60 municípios do Litoral Catarinense. As suas atividades/ações buscam despertar a valorização e o fortalecimento da cultura açoriana, bem como demonstrar que seus valores são importantes para o desenvolvimento da realidade social e econômica das comunidades envolvidas (UFSC, 2014a).

Elas envolvem pesquisadores, professores, alunos, técnicos administrativos em educação, e outros colaboradores com diferentes habilidades. Muitos projetos merecem destaque no que tange ao envolvimento com as comunidades: o Troféu Açorianidade, o Projeto Saber Fazer, o 
O núcleo de estudos açorianos: um olhar sobre a extensão na Universidade Federal de Santa Catarina

Mapeamento da Cultura de Base Açoriana e a Festa da Cultura Açoriana de Santa Catarina. (UFSC, 2014a).

O Troféu Açorianidade foi criado, em 1996, com o objetivo de reconhecer e valorizar o trabalho de Instituições, Pessoas e Empresas, em prol da Cultura de Base Açoriana do Estado de Santa Catarina. Desde a sua criação, a referida premiação acontece anualmente e a indicação dos profissionais, empresas e instituições que concorrerão ao troféu é realizada pelos componentes do Conselho Deliberativo que, posteriormente participam também da eleição dos agraciados. (UFSC, 2014a).

Outro Projeto desenvolvido pelo NEA é o Saber Fazer, que tem como objetivo estimular, valorizar e preservar as práticas artesanais tradicionais desenvolvidas pelos descendentes de açorianos como o crivo, a renda de bilro, a tecelagem, a cerâmica figurativa e utilitária, o artesanato com escama de peixes, entre outros. (UFSC, 2014a).

O Saber Fazer incentiva os artesãos ao uso de matérias-primas disponíveis na região para produzirem seus trabalhos conforme os conhecimentos tradicionais aprendidos com os idosos, passado por gerações, além de promover oficinas com esses artesões para o repasse dessas técnicas de produção. Destaca-se que os produtos tradicionais estão despertando outros usos e aplicações, ao que se chama de inovação cultural. (UFSC, 2014a).

Como exemplos desta inovação se destaca a renda de crivo, antes utilizada apenas para o vestuário dos nobres e do clero e que agora reaparece aplicada em detalhes de vestuários e outras formas de artesanato. A renda de bilro também aderiu a soluções criativas, migrando do enxoval para as roupas de praia o que garante a sobrevivência de cerca de centenas ou, mais de uma centena de artesãos no litoral catarinense. Com este Projeto, o NEA oferece também cursos que ensinam a aprimorar a apresentação do produto buscando agregar mais valor e fortalecer o processo cultural açoriano. (UFSC, 2014a).

O Projeto Mapeamento da Cultura de Base Açoriana consiste num curso de formação dos professores da rede municipal, estadual e privada de ensino fundamental e médio, em parceria com as prefeituras municipais, para o mapeamento da cultura de base açoriana do Estado de Santa Catarina. Ele atua de forma integrada nos campos da educação, cultura, turismo e trabalho. Este Projeto tem como objetivo principal, resgatar os valores culturais, contribuindo na geração de uma nova fonte de renda e de trabalho em cada comunidade envolvida no Projeto, agregando valores ao artesanato, folclore, festas populares, entre outros. (UFSC, 2014a).

A identificação e registro das manifestações culturais relacionadas à cultura açoriana segue um roteiro definido pelo NEA, e a mesma é desenvolvida pelas comunidades envolvidas. Os temas indicados (áreas) no roteiro para o referido mapeamento são: folclore, arquitetura, 
O núcleo de estudos açorianos: um olhar sobre a extensão na Universidade Federal de Santa Catarina

produção artesanal, gastronomia, religiosidade, literatura popular, jogos e brinquedos, e meios de transportes populares. (LACERDA; ALVES, 2012).

Os dados do mapeamento servem de apoio para toda a comunidade interessada na cultura açoriana bem como para pesquisas universitárias, programas de ações públicas e de difusão cultural, mas especialmente, ao público ligado à escola. Professores, pais e alunos podem ter acesso aos dados de forma estruturada, podendo organizar e participar de atividades pedagógicas no campo da cultura popular regional.

A Festa da Cultura Açoriana (AÇOR) é outro importante Projeto desenvolvido pelo Núcleo. Este Projeto foi criado em 1994 e mostra o significado e a importância da herança

cultural deixada pelos açorianos. É uma Festa anual que possui como característica principal o fato de ser itinerante, sendo realizada a cada ano em uma cidade diferente do litoral catarinense, no qual se faz uma mostra do que existe de mais autêntico e representativo sobre a cultura de base açoriana. (UFSC, 2014a).

O AÇOR busca fortalecer as relações entre a cultura e a arte com as atividades de ensino, pesquisa e extensão universitária, sensibilizando estudantes, docentes e servidores técnicos administrativos em educação como também, a comunidade externa em geral, da importância da cultura na formação de uma sociedade mais humanizada. Nesta Festa, são apresentados os trabalhos realizados nas escolas municipais e estaduais, a partir de cursos de formação de professores ministrados pela UFSC por meio do NEA, nos quais os alunos aprendem e reconhecem a cultura local, presente na formação social da região, enquanto patrimônio cultural. (UFSC, 2014a).

O Evento em comento é totalmente gratuito e estruturado a partir da oferta de conteúdos culturais e artísticos, estendendo suas ações para além dos muros universitários, buscando contribuir para a formação cultural e artística de toda a comunidade. (UFSC, 2014a).

As referidas ações realizadas pelo Núcleo de Estudos Açorianos materializam a sua atuação por meio das atividades de extensão da UFSC, que, desde a sua criação, vem trabalhando a cultura como um processo na perspectiva do desenvolvimento humano e social.

\section{POLÍTICA DE EXTENSÃO}

Historicamente, a universidade como instituição social (CHAUÍ, 2003), produtora de conhecimentos, foi alvo de disputas ideológicas colocando em cheque a sua natureza, sua função social e o seu processo de gestão. 
O núcleo de estudos açorianos: um olhar sobre a extensão na Universidade Federal de Santa Catarina

Para conceber a universidade como uma instituição social, é necessário compreender que sua gestão difere da gestão de outra organização qualquer. Sua função vai além da formação de profissionais para o trabalho. Ela deve contribuir de forma efetiva na transformação da sociedade por meio do conhecimento baseado em valores como a justiça e o bem-estar social. A universidade deve atuar de forma a responder às preocupações, exigências e necessidades da sociedade, e às demandas políticas da comunidade. (CHAUÍ, 2003).

Segundo Burigo (2003), a instituição universidade é um espaço privilegiado, um espaço para o diálogo, para discussão política, social e econômica, ela é o fio condutor da sua aventura intelectual, mesmo tendo a sua função crítica ameaçada pelo mercado que é um impositor na constituição da sua essência, ou seja, o processo da formação como uma prática educativa e social.

Com isso, o desafio que se apresenta é que os gestores universitários tenham a clareza que a universidade, como instituição social é também a executora de políticas públicas com vistas a melhoria do nível de qualidade de vida da sociedade.

A gestão universitária, como instituição social, potencializa a dialogicidade no processo das suas ações, bem como, a preservação da coisa pública, negando a racionalidade instrumental proveniente do espaço privado, onde o lucro e a mercantilização dos serviços prevalecem. (BURIGO, 2003).

As políticas públicas também delimitam as ações do processo de gestão no que tange as diretrizes materializadas por meio das determinações legais. Isto posto, as ações da gestão no contexto da Instituição, tendo como foco a atividade de extensão, entre outros fatores como a formação do gestor e as condições de trabalho é mediada pela política de extensão da UFSC.

As ações de extensão desenvolvidas pela Universidade Federal de Santa Catarina fundamentam a Política Institucional, em atendimento as diretrizes da Política Nacional de Extensão (FORPROEX, 2012). Estas ações são gerenciadas pela Pró-Reitoria de Extensão (PROEX), instituída em 2012, devido ao desdobramento da então Pró-Reitoria de Pesquisa e Extensão (PRPE). Tem por "finalidade articular e apoiar a execução da política de extensão da UFSC, seja através de ações específicas dos departamentos de ensino, seja através de ações institucionais, buscando uma integração mais efetiva da realidade social com as atividades realizadas na universidade". (UFSC, 2014b, p. 01).

No âmbito da política institucional de extensão, a Pró-Reitoria de Extensão oferece apoio financeiro aos projetos de extensão por meio do PROBOLSAS que tem por objetivo estimular a participação dos estudantes de graduação nos projetos de extensão desenvolvidos pela comunidade acadêmica por meio de auxílio na forma de bolsas (UFSC, 2014b). 
O núcleo de estudos açorianos: um olhar sobre a extensão na Universidade Federal de Santa Catarina

Outro programa gerenciado pela PROEX é o PROEXTENSÃO, com o objetivo de apoiar financeiramente ações de extensão relacionadas ao ensino e à pesquisa envolvendo alunos, servidores docentes e técnico-administrativos em educação, em atuação conjunta com a comunidade. (UFSC, 2014b).

Conforme Nogueira (2000, p. 63) “a natureza pública da universidade se confirma na proporção em que diferentes setores da população brasileira usufruam dos resultados produzidos pela atividade acadêmica". Entre outras ações gerenciadas pela PROEX (UFSC, 2014b) que se constituem como políticas de extensão da Universidade, destaca-se: a Sala Verde; o Núcleo de Estudos da Terceira Idade; a Semana de Ensino, Pesquisa e Extensão; entre outros, que reforçam o processo de interação da UFSC com a sociedade, como um intercâmbio de possibilidades concretas com quiçá possíveis processos de transformação sociais.

Por meio das atividades extensionistas, o NEA tem como essência do desenvolvimento de sua atividade a cultura como um processo de fortalecimento dos saberes e valores de uma dada comunidade. Suas ações negam a mera transmissão de informações técnicas, ao contrário, é um processo de troca de saberes, onde a Universidade apresenta o resultado de um trabalho coletivo, inter-relacionando o ensino, a pesquisa e extensão. (UFSC, 2014a).

Neste sentido, a política de extensão da UFSC reflete as concepções desenvolvidas ao longo do tempo das diretrizes das Políticas Públicas da Extensão Universitária, que se constitui num processo histórico que vem caminhando na construção de documentos que orientam e contribuem para o reconhecimento e fortalecimento da extensão como prática acadêmica que interliga a universidade com a sociedade. (PEREIRA, 2015).

No processo histórico de desenvolvimento da instituição universidade, ela necessitou repensar o seu papel no processo de desenvolvimento com e para a sociedade, à medida que busca mecanismos para sobreviver e adaptar-se na sociedade, diante de cada realidade: das condições locais, de cada região e de cada país. (BURIGO, 2003).

A atividade de extensão na universidade surgiu no Século XIX, em Oxford, na Inglaterra, com o advento da Revolução Industrial. Porém, de acordo com Burigo (2003), a atividade universitária de extensão, é uma expressão típica do modelo norte-americano de universidade, que tinha por objetivo compartilhar com a sociedade que surgia, ou seja, com a sociedade industrial, as suas atividades e descobertas.

A Constituição Federal Brasileira (BRASIL, 1998) marca um importante momento para a extensão universitária reconhecendo e fortalecendo o movimento em torno da concepção de extensão e da indissociabilidade com o ensino e a pesquisa. 
O núcleo de estudos açorianos: um olhar sobre a extensão na Universidade Federal de Santa Catarina

Diante deste cenário, o princípio da indissociabilidade entre as atividades de ensino, pesquisa e extensão passa a ser associado a prática da gestão universitária. Todavia, pesquisas apontam, diante da literatura investigada, que a extensão universitária, historicamente, muitas vezes foi mal compreendida, dificultando sua projeção no mesmo nível que o ensino e a pesquisa, atividades consagradas historicamente no contexto universitário. De acordo com Nogueira (2000), a extensão era limitada a mecanismo de acessibilidade ao conhecimento gerado nas instituições de ensino superior na forma de cursos, ou seja, uma via de mão única de disseminação do conhecimento.

O Fórum de Pró-Reitores de Extensão das Universidades Públicas Brasileiras (FORPROEX, 2001), fundado em 1987, buscou preencher uma lacuna de regulamentação na área da extensão. Assim, o caminho da universidade para a sociedade e vice-versa deixou de ser unilateral. Começou a existir uma preocupação em escutar as expectativas produzidas pela sociedade com o objetivo de buscar uma relação de reciprocidade e de mediação. Uma relação onde o saber científico possa se associar ao saber popular, a teoria, a prática em constante e contínuo movimento de desenvolvimento.

Para o FORPROEX (2001, p. 05) “a extensão universitária é um processo educativo, cultural e científico que articula o ensino e a pesquisa de forma indissociável e viabiliza a relação transformadora entre a Universidade e a Sociedade".

A partir das ações do Fórum Nacional de Pró-Reitores de Extensão das Universidades Públicas Brasileiras, em 1998 iniciou-se o processo de construção do Primeiro Plano Nacional de Extensão (FORPROEX, 2001) em parceria com a Secretaria de Educação Superior (SESu) do Ministério da Educação (MEC), que sistematizou diretrizes gerais da extensão dando suporte as ações da gestão universitária.

A Política Nacional de Extensão (FORPROEX, 2012), está norteada pelos princípios de desenvolver atividades, objetivando a produção e a preservação cultural e artística como relevantes para a afirmação do caráter nacional e de suas manifestações regionais.

Para Santos (2011) a extensão faz parte de um processo que envolve olhares diferentes e interesses diversos que interferem na prática cotidiana das instituições como: grupos sociais populares, comunidades locais e regionais, setor público e privado entre outros. Entretanto, o autor destaca a importância de se evitar que as atividades de extensão sejam focadas em atividades rentáveis, descaracterizando o papel principal da extensão que possibilita as transformações sociais, caracterizando-se como elo de integração entre universidade e sociedade, pensar e fazer, da relação teoria e prática no processo de produção do conhecimento. 
O núcleo de estudos açorianos: um olhar sobre a extensão na Universidade Federal de Santa Catarina

De acordo com Pereira (2015) é possível pontuar que a Extensão Universitária é compreendida como uma prática de gestão universitária, integrando as atividades de ensino e pesquisa de forma indissociável. Está ligada a própria função da Universidade como instituição social, tendo um compromisso efetivo com o social. Todavia a discussão de concepção sobre a extensão universitária e suas relações com a sociedade é fruto de um processo histórico, um processo contínuo de negação e de afirmação desta mediada relação.

Neste contexto, diante das ações das atividades de extensão, tendo como fenômeno de estudo a gestão das atividades de extensão desenvolvidas pelo NEA, se faz relevante refletir sinteticamente, sobre as diretrizes da Política de Cultura.

\section{POLÍTICA DE CULTURA}

Partimos da concepção de cultura como um processo social (PEREIRA, 2015). Inicialmente resgatamos Santos (2006) quando contextualiza que a cultura expressa os conflitos e os interesses dominantes da sociedade e das pessoas que dela participam, por isso, nada do que é cultural pode ser estático, permanente. Neste contexto, a cultura algo dinâmico, em constante movimento.

Assim, tratar a questão da cultura requer situá-la na qualidade de um bem coletivo assim como as outras diversas áreas governamentais (saúde, educação, meio-ambiente, entre outras). Para tanto, se faz pertinente, uma política pública que possibilite condições de incentivo e valorização da difusão das manifestações culturais. Sendo que as práticas culturais possam se desenvolver, para que sejam incorporadas a vida social não simplesmente como evento, mas como modo de transformação e enriquecimento individual e coletivo. (CALABRE, 2005).

Para Rubim e Barbalho (2007), no contexto da sociedade democrática, são consideradas políticas públicas apenas aquelas que são discutidas, legitimadas e negociadas com a sociedade. No Brasil, seguindo a lógica neoliberal, durante muito tempo, a cultura foi tratada como negócio, no qual o Estado se ausentou e a política cultural foi confundida com incentivo fiscal.

Assim, com vistas à interação do Estado e a da sociedade na perspectiva da cultura ocorreu em 2005, a Primeira Conferência Nacional de Cultura, que delineia diretrizes para a constituição de uma Política Pública de Cultura. (RUBIM; BARBALHO, 2007).

Conforme Rubim e Barbalho (2007, p. 09), a Primeira Conferência Nacional de Cultura foi "uma forma encontrada para viabilizar a unificação da política cultural e a promoção de 
O núcleo de estudos açorianos: um olhar sobre a extensão na Universidade Federal de Santa Catarina

encontros nacionais de cultura, nos quais participam representantes culturais de todos os estados da federação".

$\mathrm{Na}$ referida Conferência, foi definido que a discussão sobre o papel do Estado na cultura deve ser feita em cada país de forma diferente. Cada nação tem sua própria história e práticas culturais peculiares. No caso do Brasil, onde a diversidade interna é um dos traços mais fortes e mais nítidos da cultura, as estratégias de gestão pública necessitam ser pensadas tanto como diretrizes gerais nacionais, quanto em termos de ações regionalizadas. (BRASIL, 2007a).

A mobilização por meio da Primeira Conferência Nacional de Cultura objetivou envolver não somente os atores da sociedade civil, mas os próprios entes federados. Buscou firmar alianças, discutir, mobilizar e eleger propostas prioritárias para as políticas públicas, de âmbito nacional, a partir das proposições encaminhadas pelas etapas anteriores realizadas das conferências estaduais, municipais, intermunicipais e seminários setoriais de cultura. (BRASIL, 2007a).

A Primeira Conferência Nacional de Cultura cumpriu a importante função de promover a retomada do diálogo entre os diversos níveis de governo responsáveis pela gestão da cultura, trazendo como elemento inovador fundamental a participação da sociedade civil. (CALABRE, 2010).

Em março de 2010, se realizou a II Conferência Nacional de Cultura, onde o tema geral foi: Cultura, Diversidade, Cidadania e Desenvolvimento. Nesta Conferência foi aprovado pelo Congresso Nacional o Primeiro Plano Nacional de Cultura (PNC) (BRASIL,2012). Um Plano decenal que tem como um dos principais objetivos, marcar o efetivo ingresso da área da cultura no campo das políticas públicas. As discussões realizadas demonstraram a necessidade de se criar uma política pública específica para a área de cultura. (CALABRE, 2010).

De acordo com investigações realizadas (PEREIRA, 2015), no que diz respeito ao processo de gestão da cultura, é possível afirmar que está havendo, no Brasil, um processo de transformação das políticas culturais. A presença da cultura no campo das políticas públicas é muito recente, a institucionalização da área da cultura no conjunto das políticas públicas é um dos principais desafios a ser enfrentado.

Com a Constituição Federal (BRASIL, 1998), o direito à cultura está garantido nas legislações estaduais, e em leis orgânicas municipais. O desafio que se impõe é o de transformar a lei em realidade, a política pública em ações de gestão para acompanhar e avaliar a implantação das mesmas.

Conforme Calabre (2005), qualquer processo de gestão requer diretrizes, planejamento, execução e avaliação de resultados, e, com a cultura, não é diferente. 
O núcleo de estudos açorianos: um olhar sobre a extensão na Universidade Federal de Santa Catarina

No âmbito da Universidade Federal de Santa Catarina, conforme Relatório de Atividades da Secretaria de Cultura (UFSC, 2013a), programas e projetos voltados à Política Cultural estão sendo desenvolvidos.

[...] a gestão deve estar voltada à criação de meios (materiais e imateriais) que permitam, no nosso caso, que estudantes, docentes e técnicoadministrativos em educação concebam e realizem ações e projetos culturais empregando, investigando e ampliando conhecimentos que edificam áreas da cultura e/ou as linguagens artísticas. Ao mesmo tempo, deve promover e garantir a ampliação dos repertórios artístico culturais da comunidade acadêmica (desde a Educação Infantil à Pós-Graduação) e da sociedade de forma mais ampla, perspectivando o fortalecimento, a diversificação e a ampliação da atuação social, bem como científica da UFSC em nível local, estadual, nacional e internacional (UFSC, 2013a, p.08).

No contexto da Política Institucional de Cultura, em consonância com as diretrizes da Política Nacional de Cultura, a Universidade Federal de Santa Catarina, vem gestando Programas por meio de Bolsas, com vistas ao fomento de ações na área cultural.

O Bolsa Cultura é um programa de bolsa de extensão vinculado às ações de arte e cultura, oferecendo, auxílio financeiro a estudantes de graduação, estimulando-os à participação nos projetos de cultura da UFSC (UFSC, 2014d). Outra ação é o Programa de apoio às ações de Cultura (PROCULTURA). Esse Programa apoia financeiramente, no todo, ou em parte, ações de cultura, propostas por servidores docentes e técnicos administrativos em educação, que tenham relação com o ensino, a pesquisa e a extensão universitária.

Os supracitados Programas fazem parte de uma política de editais, lançados pela Secretaria de Cultura da UFSC (SeCult), fundamentais para democratizar, socializar e estimular a vida cultural da Universidade e na sua inter relação com a sociedade. Além de contemplar projetos de diversas unidades de ensino e setores da Universidade, eles abrangem diversas áreas artísticas, como: cinema, teatro, fotografia, dança, música, entre outros (UFSC, 2014g).

No que diz respeito às ações do NEA, como um projeto de extensão da Secretaria de Cultura da UFSC, este vai ao encontro das diretrizes do PNC, quando se propõe a:

[...] estimular a criação de centros de referência e comunitários voltados às culturas populares, ao artesanato, às técnicas e aos saberes tradicionais com a finalidade de registro e transmissão da memória, desenvolvimento de pesquisas e valorização das tradições locais. (BRASIL, 2012, p. 192). 
O núcleo de estudos açorianos: um olhar sobre a extensão na Universidade Federal de Santa Catarina

O NEA se materializa como uma política institucional de cultura e extensão, quando efetivamente estimula o ensino, a pesquisa, o resgate e a valorização da cultura açoriana em Santa Catarina.

Todavia, a gestão da atividade de extensão por meio das ações a serem desenvolvidas pelo NEA, é um desafio a ser compreendido no processo da relação mediada pela Política Institucional de Extensão e pela Política Pública de Cultura, que são congruentes no formalismo da lei, fortalecendo, teoricamente, o papel da universidade como instituição social. (CHAUI, 2003).

Diante do exposto, é possível afirmar que as políticas públicas determinam as políticas institucionais, por isso, é fundamental um processo de gestão que planeje diretrizes concretas para a manutenção e o fortalecimento de projetos de cultura e extensão, como o NEA na UFSC.

\section{O OLHAR DOS GESTORES}

O delineamento da pesquisa se constituiu (PEREIRA, 2015), quanto aos fins, de natureza descritiva; e, quanto aos meios, como pesquisa de campo, estudo de caso, bibliográfica e documental, de natureza qualitativa, tendo como fonte direta das informações, o ambiente natural onde os gestores, como sujeitos da pesquisa atuam. Segundo Triviños (1987), a pesquisa qualitativa, visa estudar os sujeitos em sua realidade, por isso se desenvolve no campo em que o fenômeno a ser pesquisado acontece.

Conforme Triviños (2001), a pesquisa qualitativa objetiva colher generalidades, que podem ou não serem aceitas pela população, a qual estão inseridos os sujeitos da pesquisa, porém em nenhum momento, a pesquisa busca generalizar os seus resultados, pois, no processo de interação e desenvolvimento da investigação, estão relacionados o contexto cultural do(s) pesquisador(es) e/ou à atividade diária realizada como profissional.

Os sujeitos participantes da pesquisa (PEREIRA, 2015), foram gestores da UFSC (Reitores; Pró-Reitores de Extensão, Secretários de Cultura e Coordenadores do NEA), dos últimos 10 (dez) anos envolvidos diretamente no processo de gestão da atividade de cultura e de extensão da Instituição, totalizando 05 sujeitos.

Além da pesquisa bibliográfica e documental, a coleta de informações ocorreu também por meio da entrevista semiestruturada com os gestores (PEREIRA, 2015). Para a elaboração do roteiro da entrevista semiestruturada, em observância ao objetivo inicialmente proposto, foram delimitadas três categorias, que respaldaram a análise e interpretação das informações coletadas: o 
O núcleo de estudos açorianos: um olhar sobre a extensão na Universidade Federal de Santa Catarina

Núcleo de Estudos Açorianos da Universidade Federal de Santa Catarina; Política Institucional de Extensão; e, Política Pública de Cultura.

$\mathrm{Na}$ primeira categoria abordada, na qual tratou do Núcleo de Estudos Açorianos da UFSC, foram realizadas perguntas que objetivaram investigar sobre o NEA, sua atuação bem como o seu processo histórico. Neste contexto, foi possível perceber que todos os entrevistados possuem conhecimento das ações desenvolvidas pelo NEA e afirmam que a sua atuação junto a comunidade externa mostra que ele atinge a sua finalidade de valorização, preservação e divulgação da cultura açoriana potencializando o papel social da Universidade.

Entretanto, ficou evidenciado que no interior da Universidade, a atuação do NEA não é tão reconhecida, como fora dela. Esta falta de conhecimento das atividades desenvolvidas e gestadas pelo NEA, na UFSC aponta a existência de uma fragilidade no processo de gestão, que está diretamente vinculado à existência de uma política institucional que venha dar suporte de forma mais objetiva e eficaz para a manutenção e fortalecimento de projetos extensionistas como o NEA. Este Núcleo é acolhido desde a década de 80, pelo seu processo histórico na UFSC, mas não como uma ação constitutiva de uma Política Institucional de Cultura e Extensão. Sua visibilidade é mais concreta na Sociedade do que perante a própria UFSC.

No que tange a segunda categoria, a Política Institucional de Extensão, na visão dos entrevistados, foi possível perceber que todos concebem a Extensão Universitária como uma das funções essenciais que compõem os pilares da instituição universidade, ou seja, ensino, pesquisa e extensão. A extensão para os gestores entrevistados, é vista como uma possibilidade concreta de interação com a sociedade, potencializando a sua função social que vem ao encontro da política de extensão estabelecida pelo Fórum Nacional de Pró-Reitores de Extensão das Universidades Públicas Brasileiras. (FORPROEX, 2012).

Contudo, esta concepção muitas vezes, não se materializa na prática da gestão, os gestores conhecem a política extensionista concebida pelo FORPROEX (2012), mas com relação à Política Institucional de Extensão, registram que na Universidade, em cada mudança de gestão, há também uma descontinuidade nos programas/ ações de extensão, prejudicando assim o compromisso da própria atividade de extensão com a sociedade.

A fragilidade da Política Institucional de Extensão, apontada pelos gestores mostra o distanciamento existente na concepção de política que perpassa pelo processo da gestão. Pois na concepção dos gestores há um elencado de ações extensionistas na UFSC (UFSC, 2014b), muitas vezes desarticuladas entre si e não constituindo uma política institucional. 
O núcleo de estudos açorianos: um olhar sobre a extensão na Universidade Federal de Santa Catarina

Por outro lado, esta fragilidade da concepção e constituição de uma política institucional, está também intimamente ligada ao processo de formação destes mesmos gestores, no que tange ao processo de gestão e de políticas públicas.

Quanto a terceira e ultima categoria, a Política Pública de Cultura, os entrevistados demonstram certo conhecimento e consideram que o Brasil vive um novo paradigma, com políticas culturais mais duradouras, voltada ao modelo de gestão compartilhada.

Nas falas dos entrevistados ficou evidente também que concebem a cultura como um processo social, abrangente, um meio de transformação e enriquecimento do ser humano. Todavia, apontaram uma lacuna com vistas a se constituir como uma Política de Cultura na UFSC alinhada a Política Nacional de Cultura.

Considerando a importância da cultura no processo de desenvolvimento humano e no fortalecimento da institucionalidade democrática, no âmbito da Universidade, os entrevistados acreditam que a cultura está ligada ao ensino, pesquisa e extensão, articulando as políticas culturais com as áreas econômicas e sociais.

Por outro lado, os gestores entrevistados, apontam que desconhecem que existam na UFSC diretrizes alinhadas a Política Pública de Cultura. Com relação a Política Institucional de Cultura, na visão dos gestores foi evidenciado também, um distanciamento entre as normas formais existentes (UFSC, 2013a) da realidade concreta vivenciada pelos gestores, assim como foi constatado também quanto a Política Institucional de Extensão.

Todavia, diante do processo de análise, é indiscutível que o NEA é uma ação de extensão, reconhecido pelos gestores diante da sua finalidade e do seu processo histórico. Porém, para o fortalecimento deste Núcleo como uma prática de gestão é possível apontar a carência de constituição de uma Política Institucional de Cultura.

\section{CONSIDERAÇÕES FINAIS}

Resgatando o objetivo inicialmente proposto de compreender na visão dos gestores sobre as ações do Núcleo de Estudos Açorianos no processo de desenvolvimento da atividade de extensão da UFSC, é possível apontar que o NEA, vem se constituindo como uma prática de gestão desde a década de 80, como uma atividade de extensão universitária, mas não como uma ação extensionista de uma Política Institucional de Cultura e Extensão. 
O núcleo de estudos açorianos: um olhar sobre a extensão na Universidade Federal de Santa Catarina

Neste contexto, a contradição que se evidencia na presente pesquisa (PEREIRA, 2015), é que o NEA, ao mesmo tempo que é situado como prática de gestão, esta prática de gestão é negada pela carência de uma Política Institucional de Cultura e de Extensão.

Salvo melhor Juízo, a superação desta contradição perpassa pelo processo de formação dos próprios gestores. Pois entre o compromisso político como gestor e a competência técnica de ser gestor, há um longo caminho a ser percorrido que perpassa pelo processo de formação.

Neste contexto, o NEA como atividade de extensão e cultura fica à mercê do desejo da prática de gestão, desarticulado de um querer institucional, de uma política institucional. Isto posto, com vistas a potencializar ações para a manutenção e fortalecimento do NEA como uma atividade de cultura e extensão da UFSC, propomos:

a) Proporcionar cursos de formação para os gestores, para o exercício da sua função gerencial junto a UFSC em parceria com o setor de Capacitação da Universidade;

b) Capacitar os gestores diante do processo de desenvolvimento das políticas públicas destinadas às universidades com vistas a compreender as políticas públicas implementadas pelo Governo Federal por meio de minicursos;

c) Promover ações compartilhadas com vistas ao desenvolvimento institucional, entre as áreas de extensão e cultura e a área de Planejamento da Instituição; e,

d) Promover atividades buscando uma maior interação do NEA com a comunidade universitária como oficinas, debates, reuniões e outras, tendo como tema a cultura açoriana.

Diante dos resultados obtidos, almejamos que as reflexões ora realizadas suscitem novas discussões visando repensar o desenvolvimento das ações do Núcleo de Estudos Açoriano, no processo de desenvolvimento da atividade de extensão e cultura da UFSC, como uma ação de fortalecimento da cultura açoriana no processo de mediação com a sociedade.

\section{REFERÊNCIAS}

BRASIL. Constituição da República Federativa do Brasil: promulgada em 05 de outubro de 1988. 18. ed. atual. e ampl. São Paulo: Saraiva, 1998.

As metas do plano nacional de cultura. Brasília: Ministério da Cultura, 2012. Disponível em: <http://www.fundacaocultural.ba.gov.br/colegiadossetoriais/As-Metas-doPlano-Nacional-de-Cultura.pdf>. Acesso em: 25 jul.2013. 
O núcleo de estudos açorianos: um olhar sobre a extensão na Universidade Federal de Santa Catarina

BÚRIGO, Carla Cristina Dutra. O trabalho acadêmico do professor universitário no processo de desenvolvimento do espaço público na universidade federal: um estudo de caso na Universidade Federal de Santa Catarina e na Universidade Federal do Rio Grande do Sul. 2003. Tese (Doutorado em Educação) - Universidade Federal do Rio Grande do Sul, Faculdade de Educação, Porto Alegre: UFRGS, 2003.

CALABRE, Lia (Org.). Políticas culturais: diálogo indispensável. Rio de Janeiro: Edições Casa de Rui Barbosa, 2005.

A I Conferência Nacional de Cultura: Análises das propostas de diretrizes. In:

Políticas culturais no Brasil: história e contemporaneidade. Fortaleza: Banco do Nordeste do Brasil, 2010.

CHAUÍ, Marilena. A universidade pública sob nova perspectiva. Revista Brasileira de

Educação, São Paulo, n. 24, set./dez. 2003. Disponível em:

<http://www.scielo.br/pdf/rbedu/n24/n24a02.pdf>. Acesso em: 24 jul. 2013.

CHEPTULIN, Alexandre. A dialética materialista: categorias e leis da dialética. São Paulo:AlfaOmega, 1982.

FORPROEX - FÓRUM DE PRÓ-REITORES DE EXTENSÃO DAS UNIVERSIDADES PÚBLICAS BRASILEIRAS. Plano Nacional de Extensão Universitária. Ilhéus: Editus, 2001. Extensão Universitária, v.1.

Política Nacional de Extensão Universitária. 2012. Disponível em:

<http://www.renex. org.br/documentos/2012-07-13-Politica-Nacional-de-Extensao.pdf>. Acesso em: 14 de mai. 2014.

LARAIA, Roque de Barros. Cultura: um conceito antropológico. Rio de Janeiro: Zahar, 2009.

LEAL, João. Cultura e identidade açoriana: o movimento açorianista em Santa Catarina. Florianópolis: Insular, 2007.

LOCH, Clesar Luis; CORREIA,Guilherme Silveira. A flexibilização do trabalho e da gestão de pessoas limitadas pela racionalidade instrumental. RCA - Revista de Ciências da Administração, Florianópolis, v. 6, n. 12, p. 1-25, jul./dez. 2004. Disponível em: $<$ https://periodicos.ufsc.br/index.php/adm/article/view/869/677>. Acesso em: 12 set. 2014.

NOGUEIRA, Maria das Dores Pimentel. Políticas de extensão universitária brasileira: 19751999. Belo Horizonte: UFMG/FaE, 1999.

NOGUEIRA, Maria das Dores Pimentel (Org.). Extensão universitária: diretrizes conceituais e políticas. Belo Horizonte: Fórum Nacional de Pró-Reitores de Extensão das Universidades Públicas/UFMG, 2000.

PEREIRA, Sandra Regina Velasques. O núcleo de estudos açorianos: um olhar sobre a extensão na Universidade Federal de Santa Catarina. 2015. 105p. Dissertação (Mestrado profissional) - Universidade Federal de Santa Catarina, Centro Socioeconômico, Programa de Pós-Graduação em Administração Universitária, Florianópolis, 2015. 
O núcleo de estudos açorianos: um olhar sobre a extensão na Universidade Federal de Santa Catarina

RUBIM, Antônio Albino Canelas; BARBALHO, Alexandre (Org.). Políticas culturais no Brasil. Salvador: EDUFBA, 2007.

RUBIM, Antonio Albino Canelas. Políticas culturais do Governo Lula / Gil: Desafios e enfrentamentos. In: .; BAYARDO, Rubens (Orgs.). Políticas culturais na IberoAmérica. Salvador: Edufba, 2008. p.51-74.

SANTOS, Boaventura de Sousa. A universidade no século XXI: para uma reforma democrática e emancipatória da universidade. São Paulo: Cortez, 2011.

TRIVIÑOS, Augusto Nibaldo Silva. Introdução à pesquisa em ciências sociais: a pesquisa qualitativa em educação. São Paulo: Atlas, 1987.

Bases teórico-metodológicas da pesquisa qualitativa em ciências sociais: ideias gerais para a elaboração de um projeto de pesquisa. v. 4. Porto Alegre: Faculdades Integradas Ritter dos Reis, 2001. 151 p. v. 4. (Cadernos de Pesquisa Ritter dos Reis).

UFSC - UNIVERSIDADE FEDERAL DE SANTA CATARINA. Convênio de cooperação e intercâmbio entre a Universidade Federal de Santa Catarina, Brasil, e a Universidade dos Açores, Portugal. Florianópolis: UFSC, 1984.

Relatório de Atividades 2013. Secretaria de Cultura da UFSC. 2013. Disponível em: <http://secult.ufsc.br/>. Acesso em: 29 jul. 2014.

NEA - Núcleo de Estudos Açorianos da UFSC. 2014a. Disponível em: <http://nea.ufsc.br/>. Acesso em: 29 jul. 2014.

Pró-reitoria de extensão da UFSC. 2014b. Disponível em: <http://proex.ufsc.br/atribuicoes/>. Acesso em: 21 jul. 2014.

Secretaria de cultura da UFSC. 2014c. Disponível em: < http://secult.ufsc.br/> . Acesso em: 19 mai. 2014. 